AIDS Care, 2014

Vol. 26, No. 3, 320-325, http://dx.doi.org/10.1080/09540121.2013.819404

\title{
Complex care needs of patients with late-stage HIV disease: A retrospective study
}

\author{
Mark Halman ${ }^{\mathrm{a}, \mathrm{b}, \mathrm{c} *}$, Soo Chan Carusone ${ }^{\mathrm{d}, \mathrm{e}}$, Sarah Stranks ${ }^{\mathrm{a}, \mathrm{f}}$, Nicole Schaefer-McDaniel ${ }^{\mathrm{d}}$ and Ann Stewart ${ }^{\mathrm{c}, \mathrm{d}}$ \\ ${ }^{\mathrm{a}}$ Department of Psychiatry, St Michael's Hospital, Toronto, Canada; ${ }^{\mathrm{b}}$ Centre for Research on Inner City Health, The Keenan \\ Research Centre in the Li Ka Shing Knowledge Institute of St. Michael's Hospital, Toronto, Canada; 'Faculty of Medicine, \\ University of Toronto, Toronto, Canada; ${ }^{\mathrm{d}}$ Casey House, Toronto, Canada; ${ }^{\mathrm{e}}$ Department of Clinical Epidemiology \& \\ Biostatistics, McMaster University, Hamilton, Canada; ${ }^{\mathrm{f}}$ School of Medicine, Queen's University, Belfast, UK
}

(Received 15 November 2012; final version received 20 June 2013)

\begin{abstract}
This retrospective chart review provides a profile of an emerging population of vulnerable HIV patients with complex comorbidities. Data were abstracted from all 83 patients admitted in 2008 to Casey House, a community-based hospital dedicated to supportive and palliative care for persons with HIV in Toronto, Canada. We describe patient characteristics, including medical and psychiatric conditions, and use a Venn diagram and case study to illustrate the frequency and reality of co-occurring conditions that contribute to the complexity of patients' health and health care needs. The mean age at admission was 49.2 years $(\mathrm{SD}=10.5)$. Sixty-seven patients $(80.7 \%)$ were male. Patients experienced a mean of 5.9 medical comorbidities $(\mathrm{SD}=2.3)$ and 1.9 psychiatric disorders (lifetime Axis I diagnoses). Forty patients (48.2\%) experienced cognitive impairment including HIV-associated dementia. Patients were on a mean of $11.5(\mathrm{SD}=5.3)$ medications at admission; $74.7 \%$ were on antiretroviral medications with $55.0 \%$ reporting full adherence. Current alcohol and drug use was common with $50.6 \%$ reporting active use at admission. Our Venn diagram illustrates the breadth of complexity in the clients with $8.4 \%$ of clients living in unstable housing with three or more medical comorbidities and two or more psychiatric diagnoses. Comprehensive HIV program planning should include interventions that can flexibly adapt to meet the multidimensional and complex needs of this segment of patients. Researchers, policy-makers, and clinicians need to have greater awareness of overlapping medical, psychiatric and psychosocial comorbidities. Inclusion of the needs of these most vulnerable patients in the development of evidence-based guidelines is an important step for effectively treating, preventing, and planning for the future of HIV/AIDS care.
\end{abstract}

Keywords: HIV/AIDS; comorbidities; vulnerable populations; homelessness; mental health; HIV-associated neurocognitive disorders

\section{Introduction}

Highly Active Antiretroviral Therapy (HAART) has changed the face of the AIDS epidemic (Palella et al., 1998; Puhan et al., 2010). Many now thrive; however, a subset of people living with HIV struggle and contend with high levels of chronic medical, psychiatric and psychosocial morbidity (Rubin, Colen, \& Link, 2009; Walley et al., 2008). Patients, such as Abigail (Appendix 1) require ongoing complex care, though this aspect of HIV disease remains scarcely researched and underreported in the literature. Current clinical guidelines are most strongly informed by large randomized controlled trials. Methods used in these trials aim to maximize internal validity, resulting in the underrepresentation of complex patients (Fortin et al., 2006). It is important that clinicians, policy-makers, and researchers understand the breadth and complexity of issues that some people with HIV/AIDS are facing, so that effective resource planning can address the needs of the entire HIV population. HIV medical clinics and AIDS Service Organizations must evolve their services to meet the needs of all patients with HIV disease, including the most marginalized and vulnerable, who may not maximally benefit from traditional models of care.

In this paper, we add to the literature by describing the complex and overlapping medical, psychiatric, and psychosocial care needs of some of the most vulnerable patients living with HIV disease. We conducted data abstraction through retrospective chart review of all patients admitted to Casey House, a community-based HIV/AIDS hospital, during the course of one year. Casey House began as an HIV/AIDS hospice focused on end of life care in 1988 and evolved over time into a communitybased hospital with sub-acute inpatient care and community outreach programs that provide home care, case management, and service coordination with acute care hospitals and partner agencies in Toronto.

\footnotetext{
*Corresponding author. Email: HalmanM@smh.ca 


\section{Methods}

\section{Research setting}

The research focused specifically on the patients admitted to the 13-bed inpatient sub-acute HIV/ AIDS hospital. Individuals with HIV may be admitted for sub-acute, palliative or respite care, provided by an inter-professional team including physicians, nurses, rehabilitation therapists, and social workers.

\section{Research methods and data analysis}

We employed an in-depth retrospective chart review to collect data on patient demographics, self-reported substance use, medical and psychiatric history. Cognitive impairment was diagnosed according to the nosology for HIV-Associated Neurocognitive Disorders (Antinori et al., 2007). Data were analyzed in SPSS version 17.0.

Data are from all 83 patients admitted to Casey House between 1 January and 31 December 2008. Sixty-seven patients were admitted once, 16 patients were admitted on multiple occasions. Only first admission data are reported. Ethical approval was obtained through the St. Michael's Hospital Research Ethics Board.

\section{Results}

\section{Participant characteristics}

Patient demographics and medical and psychiatric history are summarized in Tables 1 and 2 . The majority of patients was male $(n=67 ; 80.7 \%)$ and patients' mean age was 49.2 years $(\mathrm{SD}=10.5)$. About half of the patients identified as homosexual ( $n=44$; $61.1 \%)$. Eleven patients $(13.6 \%)$ reported living on the street or in a shelter at the time of admission and five patients $(6.1 \%)$ were under-housed, staying with friends or family.

\section{Hospital stay}

Twenty-two patients $(26.5 \%)$ were admitted as a planned 14-day respite stay, while the remaining patients entered through a general admission (mean stay $=46.9$ days $(\mathrm{SD}=50.2)$ ). Patients could have multiple reasons for admission (summarized in Table 3): the most common being for supportive care with a medical focus $(86.7 \%)$ that is, failure to thrive and recovery from acute medical illness, and HAART adherence support $(20.5 \%)$.

Sixteen of the patients admitted in 2008 died at Casey House $(19.3 \%)$. The remaining patients were discharged to various locations including home
Table 1. Patient demographics $(n=83)$.

\begin{tabular}{|c|c|c|}
\hline & Frequency & Percentage \\
\hline Mean age (years) & 49.2 & $\mathrm{SD}=10.5$ \\
\hline \multicolumn{3}{|l|}{ Gender $(n=83)$} \\
\hline Male & 67 & 80.7 \\
\hline Female & 16 & 19.3 \\
\hline \multicolumn{3}{|l|}{ Marital status $(n=82)$} \\
\hline Single, never married & 46 & 56.1 \\
\hline Married, common law & 16 & 19.5 \\
\hline Divorced, separated & 16 & 19.5 \\
\hline Widowed & 4 & 4.9 \\
\hline \multicolumn{3}{|l|}{ Sexual orientation $(n=72)$} \\
\hline Homosexual & 44 & 61.1 \\
\hline Heterosexual & 24 & 33.3 \\
\hline Bisexual & 4 & 5.6 \\
\hline \multicolumn{3}{|l|}{ Ethnicity $(n=77)$} \\
\hline White & 56 & 72.7 \\
\hline Black & 8 & 10.4 \\
\hline Aboriginal & 8 & 10.4 \\
\hline Asian & 5 & 6.5 \\
\hline \multicolumn{3}{|l|}{ Citizen status $(n=75)$} \\
\hline Canadian citizen & 65 & 86.7 \\
\hline Permanent resident & 9 & 12.0 \\
\hline Refugee claimant & 1 & 1.3 \\
\hline \multicolumn{3}{|l|}{ Income source* $(n=79)$} \\
\hline $\begin{array}{l}\text { Disability and/or national pension } \\
\text { plan }\end{array}$ & 70 & 88.6 \\
\hline Employment & 2 & 2.5 \\
\hline Family support & 2 & 2.5 \\
\hline No reported income & 3 & 3.8 \\
\hline Other & 6 & 7.6 \\
\hline \multicolumn{3}{|l|}{ Housing $(n=81)$} \\
\hline Renting own dwelling & 44 & 54.3 \\
\hline Supported housing (renting) & 17 & 21.0 \\
\hline $\begin{array}{l}\text { Unstable housing (shelter, streets, } \\
\text { staying with family or friends) }\end{array}$ & 16 & 19.8 \\
\hline Homeowner & 2 & 2.5 \\
\hline Nursing home & 2 & 2.5 \\
\hline
\end{tabular}

Note: *Patients could report more than one income source.

( $n=34 ; 41.0 \%)$, hospital $(n=13 ; 15.7 \%)$, supportive housing $(n=13 ; 15.7 \%)$, community shelters $(n=4$; $4.8 \%)$, and nursing homes $(n=2 ; 2.4 \%)$.

\section{Medical history}

Patients had been living with HIV for an average of 14.8 years $(\mathrm{SD}=7.5)$. Forty-six patients $(58.2 \%)$ had CD4 counts below 200 cells $/ \mathrm{ml}$. Nine patients $(10.8 \%)$ did not have a primary care physician.

At admission, patients were taking an average of 11.5 medications $(\mathrm{SD}=5.3)$. Seventy-five percent 
Table 2. Patient medical and psychiatric history $(n=83)$.

\begin{tabular}{|c|c|c|}
\hline & Frequency & Percentage \\
\hline \multicolumn{3}{|l|}{ Medical History } \\
\hline $\begin{array}{l}\text { Average number of years living } \\
\text { with HIV }\end{array}$ & 14.8 & $\mathrm{SD}=7.5$ \\
\hline \multicolumn{3}{|l|}{ CD4 + at admission $(n=79)$} \\
\hline $\mathrm{CD} 4+<200$ & 46 & 58.2 \\
\hline $\mathrm{CD} 4+200-500$ & 23 & 29.1 \\
\hline $\mathrm{CD} 4+>500$ & 10 & 12.7 \\
\hline \multicolumn{3}{|l|}{ Viral load recorded on chart $(n=53)$} \\
\hline Viral load detectable & 32 & 60.4 \\
\hline Viral load undetectable & 21 & 39.6 \\
\hline Presence of anemia & 26 & 31.3 \\
\hline No family physician & 9 & 10.8 \\
\hline \multicolumn{3}{|l|}{ Medical co-morbidities $(n=83)$} \\
\hline $\begin{array}{l}\text { Mean number of medical co- } \\
\text { morbidities }\end{array}$ & 5.9 & $\mathrm{SD}=2.3$ \\
\hline $\begin{array}{l}\text { AIDS defining opportunistic } \\
\text { condition }\end{array}$ & 44 & 53.0 \\
\hline Respiratory disease/condition & 36 & 43.4 \\
\hline Liver disease & 24 & 28.9 \\
\hline Non-AIDS defining malignancies & 14 & 16.9 \\
\hline Cardiac disease & 16 & 19.3 \\
\hline Kidney disease & 8 & 9.6 \\
\hline AIDS defining malignancies & 5 & 6.0 \\
\hline \multicolumn{3}{|l|}{ Medications $(n=83)$} \\
\hline $\begin{array}{l}\text { Mean number of all meds at } \\
\text { admission }\end{array}$ & 11.5 & $\mathrm{SD}=5.3$ \\
\hline On HAART & 62 & 74.7 \\
\hline $\begin{array}{l}\text { Mean CPE } 2010 \text { Rank of } \\
\text { HAART regime }(n=60)\end{array}$ & 9.7 & $\mathrm{SD}=3.0$ \\
\hline $\begin{array}{l}\text { Self-reported full adherence to } \\
\text { ART }(n=60)\end{array}$ & 33 & 55.0 \\
\hline \multicolumn{3}{|c|}{ Lifetime history of psychiatric disorder $(n=83)$} \\
\hline Mean number of Axis I diagnoses & 1.9 & $\mathrm{SD}=1.1$ \\
\hline Drug misuse disorder & 52 & 62.7 \\
\hline $\begin{array}{l}\text { Cognitive disorders including } \\
\text { dementia }\end{array}$ & 40 & 48.2 \\
\hline Depressive disorder & 32 & 38.6 \\
\hline Anxiety disorder & 12 & 14.5 \\
\hline Bipolar disorder & 6 & 7.2 \\
\hline Schizophrenia disorder & 4 & 4.8 \\
\hline PTSD & 3 & 3.6 \\
\hline Adjustment disorder & 1 & 1.2 \\
\hline Other psychiatric disorder & 6 & 7.2 \\
\hline \multicolumn{3}{|l|}{ Psychiatric medications $(n=63)$} \\
\hline $\begin{array}{l}\text { Mean number of psych meds at } \\
\text { admission }\end{array}$ & 1.9 & $\mathrm{SD}=1.1$ \\
\hline Hypnotics & 40 & 63.5 \\
\hline Antidepressants & 28 & 44.4 \\
\hline Antipsychotics & 23 & 36.5 \\
\hline Psychostimulants & 3 & 4.8 \\
\hline Mood stabilizers & 1 & 1.6 \\
\hline \multicolumn{3}{|l|}{ Substance misuse $(n=83)$} \\
\hline Alcohol & 11 & 13.3 \\
\hline Any substance use (other than & 36 & 43.4 \\
\hline
\end{tabular}

Table 2 (Continued)

\begin{tabular}{lcc}
\hline & Frequency & Percentage \\
\hline Cocaine & 20 & 24.1 \\
Marijuana & 14 & 16.9 \\
Crystal meth & 7 & 8.4 \\
Other drugs & 5 & 6.0 \\
\hline
\end{tabular}

were on HAART $(n=62)$; just over half of these patients reported being adherent $(55.0 \%)$. On average, patients experienced $5.9(\mathrm{SD}=2.3)$ medical comorbidities, the most common being AIDS-defining opportunistic infections $(n=44 ; 53.0 \%)$, respiratory disease $(n=36 ; 43.4 \%)$ and liver disease $(n=24$; $28.9 \%)$.

\section{Psychiatric history, neurocognitive status, and} substance use

Psychiatric comorbidity was significant with a group mean of 1.9 lifetime Axis I diagnoses $(\mathrm{SD}=1.1)$. The most common psychiatric disorders were substance misuse ( $n=52 ; 62.7 \%)$, cognitive disorders including dementia $(n=39 ; 47.0 \%)$, and depressive disorders $(n=32 ; 38.6 \%)$. Of the 40 individuals with cognitive impairment, $18(45.0 \%)$ had mild neurocognitive impairment, and $22(55.0 \%)$ had dementia. Upon admission, 63 (75.9\%) patients were on psychotropic medications. Eight $(9.6 \%)$ had previously attempted suicide and $10(12.0 \%)$ had a bipolar or psychotic disorder. At admission, $11(13.3 \%)$ reported using alcohol and $36(43.4 \%)$ reported using other substances, most commonly cocaine $(n=20 ; 24.1 \%)$ and marijuana $(n=14 ; 16.9 \%)$.

\section{Patient complexity}

We used a Venn diagram to demonstrate the coexistence of complicating conditions (Figure 1). We defined three variables of complexity: medical complexity, psychiatric complexity, and housing instability. Medical complexity is defined as having three or more medical comorbidities. Psychiatric complexity is defined as having two or more lifetime Axis I diagnoses (which includes substance misuse and cognitive disorders). Housing instability was defined as living on the street, in a shelter or with family or friends. One patient $(1.2 \%)$ did not have any of these complexities. Seventy-seven patients $(92.8 \%)$ had two or more Axis I diagnoses, 28 patients $(33.7 \%)$ had three or more medical comorbidities, and 16 patients $(19.3 \%)$ had unstable housing. Seven patients $(8.4 \%)$ experienced all three complexity variables. 
Table 3. Reason for admission $(n=83)$.

\begin{tabular}{|c|c|c|c|c|}
\hline \multirow[b]{2}{*}{ Reason for admission } & \multicolumn{2}{|c|}{$\begin{array}{l}\text { General admission } \\
\qquad(n=61)\end{array}$} & \multicolumn{2}{|c|}{$\begin{array}{l}\text { Respite admission } \\
\quad(n=22)\end{array}$} \\
\hline & Frequency* & Percentage & Frequency* & Percentage \\
\hline Supportive care/medical focus & 51 & 83.6 & 21 & 95.5 \\
\hline ART adherence support & 11 & 18.0 & 6 & 27.3 \\
\hline End of life care & 9 & 14.8 & 0 & $\mathrm{n} / \mathrm{a}$ \\
\hline Supportive care/psychosocial focus & 7 & 11.5 & 5 & 22.7 \\
\hline Caregiver relief & 1 & 1.6 & 3 & 13.6 \\
\hline
\end{tabular}

Note: *Patients could be admitted for more than one reason.

\section{Discussion}

This chart review provides a profile of issues experienced by a segment of the evolving HIV-positive population with high care needs in Toronto. These patients are too unwell to manage independently and require a community-based flexible alternative to acute care hospitalizations. Appendix 1 provides a case example of the context and care provided.
Today, treatment with antiretroviral therapies enables the majority of the HIV-positive population in developed countries to live longer, healthier lives. However, we highlight a vulnerable population that is unable to optimally benefit from existing therapies. Nineteen percent of our patients died during their stay illuminating the fact that people with HIV disease continue to contend with early mortality. In addition

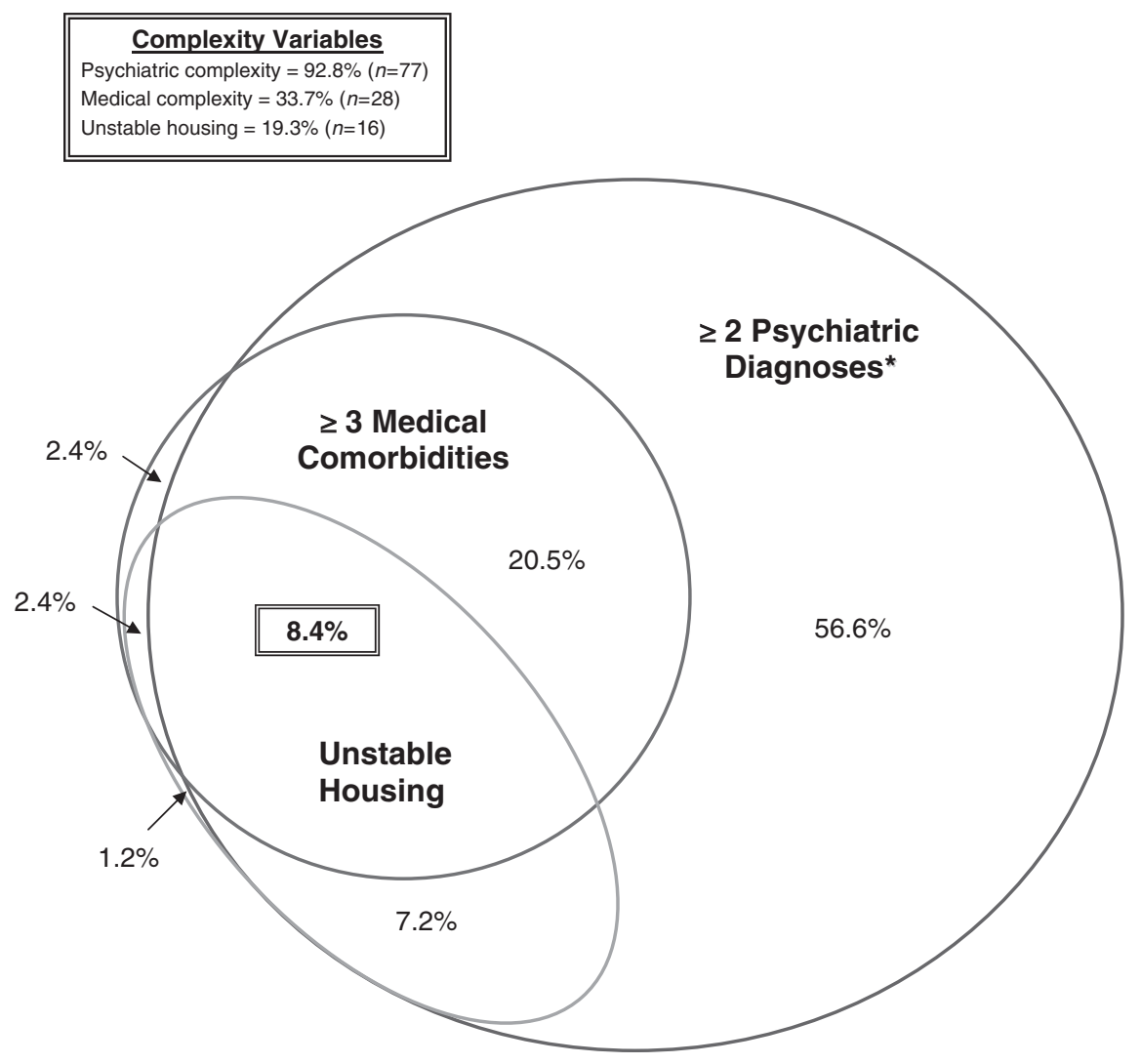

Figure 1. Patient complexity Venn diagram. This Venn diagram demonstrates the complex interaction of psychiatric history, medical morbidity and unstable housing in 83 patients. Only $1.2 \%(n=1)$ did not have any of the complexity variables.

*Note: Psychiatric diagnoses include substance misuse disorder and HIV-associated neurocognitive impairment. 
to HIV disease and considerable psychosocial challenges, patients had multiple medical comorbidities, were taking, on average, more than 11 medications, and almost half had cognitive impairment.

The co-occurrence of medical, psychiatric and psychosocial complexities in Casey House patients was significant, as illustrated in our Venn diagram. Our findings are analogous to those reported from an HIV-infected veterans' cohort. Kilbourne et al. (2001) demonstrated significant overlap of conditions when examining depressive symptoms, at-risk alcohol or illicit drug use, and two or more general comorbidities. These results emphasize the need to both, identify coexisting conditions and to improve our understanding of how they influence standard treatment protocols. As Parekh et al. (2011) recommended, this includes improving the external validity of clinical trials and incorporating the issue of multi-morbidity in clinical guidelines. Our results also highlight the need for improved coordination of medical and psychiatric care, as well as an integration of psychosocial, recovery oriented addictions and harm reduction services, to enable all patients to benefit from the advances in HIV/AIDS medicine.

Our report shares many findings with a study examining medical and psychiatric comorbidities in HIV-positive patients cared for between 1995 and 1998, at an AIDS designated long-term care facility in New Haven, USA (Selwyn et al., 2000). In their sample of patients with late stage HIV disease, they also found high rates of medical illness, HIV dementia $(32 \%)$ and psychiatric illness $(44 \%)$. As these authors noted, with the effectiveness of HAART, people are living longer with HIV and a growing number experience morbidity, marginalization, and disability. Our findings, from 10 years later in the HIV epidemic, echo this notion and demonstrate the need for interventions that can flexibly support these patients.

\section{Limitations and future directions}

Our study provides some of the missing context to the HIV/AIDS literature, focusing on complex patients in Toronto, Canada. We acknowledge that this study has important limitations. Our ability to explore clinical outcomes is limited by issues associated with chart reviews including the lack of standardized diagnoses. The use of self-reports for determining alcohol and substance use likely resulted in an underestimation of use. The complexity and often disjointed care in multiple centers, common to this population, provided additional barriers to obtaining both health and care variables. However, the importance of this study is strengthened by the inclusion of all patients seen over a 12-month period at a community-based HIV/AIDS hospital. Although stigma remains a barrier for some to seek treatment, this research design allowed us to capture marginalized and medically complex individuals, who are often not represented in prospective studies.

Planning for the future, both HIV care and research should include a holistic view of individuals with HIV, addressing their medical, psychiatric, and social needs and the various interactions between them. We believe that we need to plan for the future informed by health promotion and determinants of health models for improving the lives of those living with HIV. In order to reduce health disparities for all patients with HIV disease, comorbidities, such as psychiatric illness and addictions, and social issues, such as housing insecurity must be addressed. Practical suggestions should include key components of continuity of care that have been found to be helpful in related fields involving complex clients and vulnerable populations, such as: attending to service coordination; facilitating transitions in care; involving the meaningful voice of patients living with HIV and multiple comorbidities, and; developing care plans that are reasonable, feasible and appropriately meet individuals where they are situated (LHINC, 2011). Furthermore, we must take the effort to include complex patients in research so that we can make evidence-based decisions. Guidelines based solely on randomized controlled trials of healthier patients with HIV/AIDS may fail to address the complex care needs of the most vulnerable patients. Policy-makers must also strive to make just allocation of resources so that needs of patients such as Abigail may be met.

\section{Acknowledgments}

We would like to acknowledge the Krembil Foundation for supporting research at Casey House and Tim Guimond for providing valuable suggestions for this manuscript.

\section{References}

Antinori, A., Arendt, G., Becker, J. T., Brew, B. J., Byrd, D. A., Cherner, M., \& Wojna, V. E. (2007). Updated research nosology for HIV-associated neurocognitive disorders. Neurology, 69, 1789-1799. doi:10.1212/ 01.WNL.0000287431.88658.8b

Fortin, M., Dionne, J., Pinho, G., Gignac, J., Almirall, J., \& Lapointe, L. (2006). Randomized controlled trials: Do they have external validity for patients with multiple comorbidities? Annals of Family Medicine, 4(2), 104108. doi:10.1370/afm.516

Kilbourne, A. M., Justice, A. C., Rabeneck, L., RodriguezBarradas, M., Weissman, S., \& VACS 3 Project Team. (2001). General medical and psychiatric comorbidity 
among HIV-infected veterans in the post-HAART era. Journal of Clinical Epidemiology, 54(Suppl. 1), S22-28. doi:10.1016/S0895-4356(01)00443-7

Local Health Integration Network Collaboration Mental Health and Addictions Working Group. (2011). 'Through the door'. Ontario Local Health Integration Network. Retrieved from http://www.ofcmhap.on.ca/sites/ofcmhap.on.ca/files/LHINC\%20Mental $\% 20$ Health $\% 20$ and $\% 20$ Addictions $\% 20$ Working $\% 20$ Group $\% 20$ Report $\%$ 20-\%20Through $\% 20$ the $\% 20$ Door.pdf

Palella, F. J. Jr., Delaney, K. M., Moorman, A. C., Loveless, M. O., Fuhrer, J., Satten, G. A., ... Holmberg, S. D. (1998). Declining morbidity and mortality among patients with advanced human immunodeficiency virus infection. HIV Outpatient Study Investigators. The New England Journal of Medicine, 338(13), 853-860. doi:10.1056/NEJM199803263381301

Parekh, A. K., Goodman, R. A., Gordon, C., Koh, H. K., \& HHS Interagency Workgroup on Multiple Chronic Conditions. (2011). Managing multiple chronic conditions: a strategic framework for improving health outcomes and quality of life. Public Health Reports, 126(4), 460-471. Retrieved from http://www.publicheal threports.org/issueopen.cfm?articleID $=2684$

Puhan, M. A., Van Natta, M. L., Palella, F. J., Addessi, A., Meinert, C., \& Ocular Complications of AIDS Research Group. (2010). Excess mortality in patients with AIDS in the era of highly active antiretroviral therapy: Temporal changes and risk factors. Clinical Infectious Diseases, 51(8), 947-956. doi:10.1086/656415

Rubin, M. S., Colen, C. G., \& Link, B. G. (2009). Examination of inequalities in HIV/AIDS mortality in the United States from a fundamental cause perspective. American Journal of Public Health, 100(6), 1053-1059. doi:10.2105/AJPH.2009.170241

Selwyn, P. A., Goulet, J. L., Molde, S., Constantino, J., Fennie, K. P., Wetherill, P., ... Kennedy, C. (2000). HIV as a chronic disease: implications for long-term care at an AIDS-dedicated skilled nursing facility. Journal of Urban Health: Bulletin of the New York
Academy of Medicine, 44(2), 187-203. doi:10.1007/ BF02390530

Walley, A. Y., Cheng, D. M., Libman, H., Nunes, D., Horsburgh C. R. Jr, Saitz, R. \& Samet, J. H. (2008). Recent drug use, homelessness and increased shortterm mortality in HIV-infected persons with alcohol problems. AIDS, 22(3), 416-420. doi:10.1097/QAD. 0b013e3282f423f8

\section{Appendix 1: Casey House case study}

Abigail (name changed for reasons of confidentiality) is a 46-year-old HIV-positive Aboriginal woman with a history of schizophrenia, depression, and crack dependence. She is homeless. Following an episode of crack use she is found on the railings of a highway overpass and endorses a desire to die. Her weight is 95 pounds. She is weak with unsteady gait, poor color, hair loss and many missing teeth. She has a CD4 count of 23 and a viral load of 220,000. She has normocytic anemia, chronic Hepatitis B, and Hepatitis C. Her behavior is grossly disorganized, and she has persistent auditory hallucinations. Her personal history is marked by repeated exposures to trauma and psychosocial deprivation, including repeated sexual assaults, both as a child and as an adult, multiple arrests for prostitution and related charges, and a third grade level of education. She is brought to an acute care hospital but refuses to stay. Following counseling with her community case worker she agrees to go to a community facility for the care and support of HIVpositive clients, known as Casey House.

Following her admission to Casey House, Abigail is stabilized on IM (long-acting) risperidone and her HIV disease is treated with a combination of tenofovir/emticitibine/ lopinavir/ritonavir. She decreases her crack use, gains 45 pounds and her CD4 count rises to 145 . She sees a dentist and gets an upper plate. She begins to form stable working relationships with the care team, is able to establish stable housing and begins to contemplate treatment for her addictions. She remains supported through outpatient case management and has required readmissions to Casey House during periods of medical and/or psychiatric decline. 